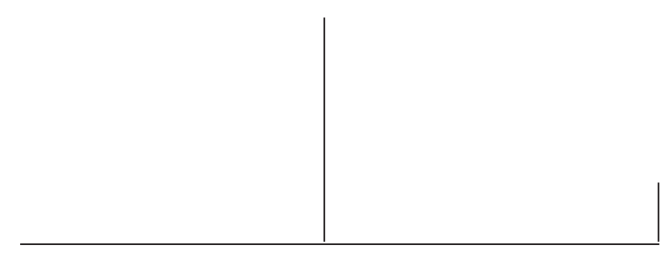

Rev. Latinoam. Psicopat. Fund., VII, 4, 135-143

\title{
Os tempos da prematuridade
}

\author{
Silvia Abu-Jamra Zornig \\ Denise Streit Morsch \\ Nina Almeida Braga
}

Este trabalho tem por objetivo discutir a clínica psicanalítica com bebês, tendo como referência um projeto de pesquisa desenvolvido com bebês pré-termo internados e suas famílias (Hospital Fernandes Figueira/Fiocruz). Parte da concepção freudiana sobre o desamparo estrutural do ser humano para analisar as vicissitudes da constituição do sujeito a partir dos diferentes tempos que se instalam nos primórdios da subjetividade: um tempo de retroação relacionado aos fantasmas e desejos parentais, um tempo de construção (Winnicott) e de continuidade relacionado aos cuidados maternos e um tempo descontínuo, traumático, que se refere aos bebês nascidos prematuramente.

Palavras-chave: Clínica psicanalítica, bebês prematuros, constituição do sujeito, intervenção precoce 


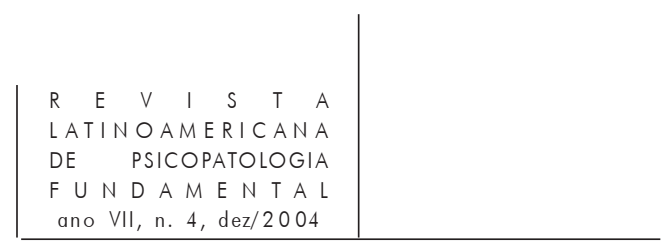

... todo ser humano é, desde a sua origem, da sua concepção, uma fonte autônoma de desejo... Françoise Dolto, 1981, p. 183

Esta citação de Françoise Dolto é instigante, pois coloca uma questão fundamental para a clínica de bebês: que estatuto dar a este ser que, apesar de imerso na linguagem (dos pais), ainda não tem ao seu dispor a linguagem verbal como principal instrumento de comunicação? Como pensar no bebê como um sujeito desejante, nos primórdios de sua constituição psíquica, antes de ter um eu auto-reflexivo? Dolto indica uma possibilidade ao ressaltar que o encontro humano inicial se define a partir do campo físico, da sinalização sensorial, das trocas e contatos corpo a corpo, baseadas na impotência da criança para sobreviver sozinha. Porém, indica a autora, a relação mãe-filho é uma relação de troca e de modulação, onde mesmo reconhecendo que o adulto dá um sentido a esta comunicação não-verbal, é preciso não esquecer que o bebê é, ao mesmo tempo, totalmente receptivo ao que vem do campo do outro, mas destinado à autonomia, a um mais além do desejo de seus pais.

As formulações da autora respondem a alguns pressupostos psicanalíticos que colocam o bebê em uma posição passiva perante o outro, partindo da noção freudiana sobre o desamparo estrutural do ser humano para teorizar a ação do desejo parental sobre o filho não só como responsável por sua sobrevivência física e psíquica, como também por seus sintomas na primeira infância (efeito dos fantasmas parentais). Ao propor que o analista de crianças pequenas só pode ocupar um lugar efetivo se reconhecer o desejo do bebê de se destacar do efeito sintomático das interferências libidinais familiares e parentais, Dolto reconhece que o bebê pode ocupar um lugar de alteridade, sendo reconhecido em seu estatuto de subjetividade e de uma promessa de autonomia futura. É interessante notar que a autora antecipa uma discussão que apareceria posteriormente pela interlocução entre a psicanálise e outras áreas de saber sobre o estatuto e o lugar dado aos bebês.

Os avanços tecnológicos da contemporaneidade como exames ultrasonográficos, estudos sobre a vida intra-uterina, avanços surpreendentes nas áreas de neonatologia e neuro-ciência tiveram o efeito não só de reduzir drasticamente a mortalidade infantil, como permitir a sobrevivência de bebês 


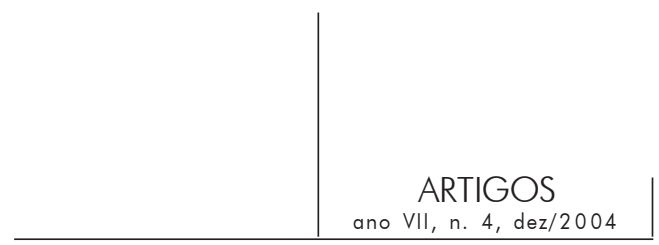

prematuros que não teriam chances de sobreviver anteriormente. Paralelamente ao avanço tecnológico e à manutenção da vida, inúmero autores iniciaram um debate intenso sobre o nascimento psicológico do bebê (Piontelli, 1995; Soulé e Cyrulnik, 1999; Busnel, 1997) sugerindo que os primórdios da constituição subjetiva antecedem o nascimento e postulando um bebê que não só reage ao meio ambiente como memoriza fatos, expressa desejos e demanda a satisfação de suas necessidades, ou seja, possui formas precoces de linguagem não-verbal e vida subjetiva.

Estes dados corroboram a visão de autores como Daniel Stern (1992) e Bernard Golse (2002), entre outros, que procuram ressaltar a dimensão desejante do lactente, postulando um bebê com competências e capacidades desde o nascimento, capacidades que podem ser transformadas em respostas e que indicam a possibilidade do bebê exercer um controle sobre o início, manutenção e término do contato social com a mãe. Golse, inclusive, utiliza o termo "transmissão intergeracional" para indicar uma transmissão em dois sentidos: dos pais para o filho, mas também do filho em direção aos pais.

A concepção freudiana sobre o desamparo estrutural do ser humano ao indicar que a prematuração biológica do bebê o coloca em uma posição de desamparo perante seus cuidadores fundamentais, fazendo com que seja necessário uma "ajuda externa" ("Projeto para uma psicologia científica", 1895) para o sujeito humano sobreviver física e psiquicamente foi o ponto de partida para a reflexão sobre o vínculo fundamental entre o bebê e seus cuidadores primordiais. No entanto, como indica Winnicott (1960), apesar de Freud ter indicado que o lactente só pode ser pensado em conjunto com os cuidados maternos, ele não se detém nesse período de vida, privilegiando trazer à tona a importância da infância através de uma ótica retroativa. Este tempo de retroação, de ressignificação, é importantíssimo quando trabalhamos na clínica da intervenção precoce, pois os fantasmas parentais, a relação da mãe com sua própria infância, a possibilidade de investir narcisicamente no filho que ali está, determina ou dificulta a instauração deste vínculo inicial.

Winnicott, no entanto, se destaca da ótica freudiana ao postular um tempo de construção, uma temporalidade contínua que possibilita ao bebê um sentimento de existir no mundo, ou seja, o surgimento de um esboço de self a partir desta continuidade temporal que é estabelecida pelo holding materno. Neste contexto, a questão do trauma do nascimento não é colocada como estrutural, mas sim como uma falha, como uma descontinuidade relacionada a uma invasão prolongada e excessiva do meio ambiente.

Assim sendo, a noção de temporalidade contínua seria introduzida pelos cuidados maternos e o trauma relacionado à descontinuidade que força o bebê a reagir, retirando-o de um estado de "existir", mobilizando angústias inimagináveis 


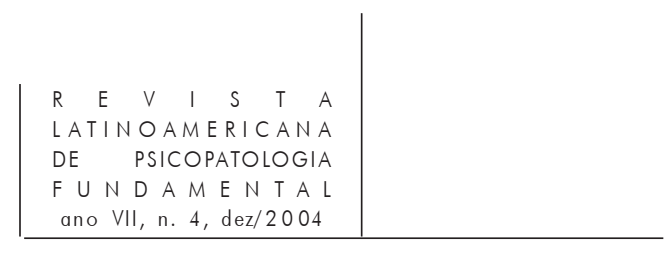

e ameaça de aniquilamento. Esta perspectiva parece se apoiar em Ferenczi (1927) que questiona a relação feita por Freud entre a angústia e o trauma do nascimento, indicando que o nascimento pode ser considerado "um triunfo" para a criança por ser o resultado de um processo: por um lado, a criança tem todas as condições de nascer e, por outro, seus pais procuram, com seus cuidados e proteção, tornar essa transição tão suave quanto possível. Ferenczi e Winnicott partem do pressuposto de que a relação inicial entre o sujeito e os cuidados maternos, entre o sujeito e o meio ambiente não é necessariamente traumática nem violenta justamente pela possibilidade de a mãe se colocar num estado de preocupação materna primária que possibilita ao bebê uma sustentação física e psicológica, um espaço de ilusão em que ele tem a sensação de onipotência (necessária) de que pode inventar, criar seus objetos internos. Ou seja, o sujeito winnicottiano se produz no espaço potencial entre a mãe e o bebê "que envolve vários tipos de tensões dialéticas de unidade e separação, de internalidade e externalidade, por meio das quais o sujeito é simultaneamente constituído e descentrado de si mesmo" (Ogden, 1996, p. 45).

Neste contexto, pensar sobre a clínica de bebês implica pensar num tipo de relação e não em um indivíduo, partindo do pressuposto de que o nascimento de um bebê provoca uma neoformação psíquica nos pais, em que a inclusão do bebê na organização psíquica da mãe é o elemento capital na criação desta neoformação. As intervenções precoces se dirigem ao enfans em um momento de vida em que a dependência ao Outro materno é predominante, sendo impossível atender o bebê sem atender a mãe ou os pais.

Isto não significa considerar o bebê uma lousa em branco, mas sim enfatizar a interdependência entre bebê-mãe. Winnicott e Stern apontam para esta dimensão ao indicarem como o nascimento de um bebê traz consigo um contexto evocativo para os pais, reativando suas representações mentais. Stern salienta que a experiência de evocar acontece no presente e não no passado e, neste sentido, as interações cotidianas com o bebê constituem o contexto evocativo presente. Os atos diários de maternagem propiciam não só uma interação presente, mas se constituem como episódios de memórias do período de bebê da mãe e, ao mesmo tempo, da maternagem que ela recebeu da própria mãe. O que transforma o contexto presente no gatilho dessas recordações é que ambos consistem nas experiências de ambos os lados da interação - da mãe e do bebê - através de uma geração.

Nesta perspectiva, as fantasias parentais sobre o bebê (bebê fantasmático) incluindo seus medos, sonhos, lembranças da própria infância, modelos de pais, ou seja, o mundo mental de suas representações, assumem o estatuto de uma ancoragem fundamental à construção do senso de self do sujeito. Da mesma forma, como ilustrou magistralmente Selma Fraiberg (1975), as fantasias maternas 


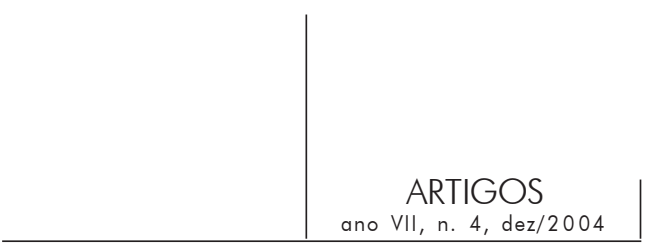

podem aparecer como "fantasmas que rondam o quarto do bebê" (p. 387), contribuindo para distúrbios no relacionamento pais-bebê e na formação dos sintomas da primeira infância.

"O mito do amor materno", parafraseando o título do livro de Elizabeth Badinter, sobre a construção do vínculo mãe-bebê, é responsável por inúmeras vicissitudes nestas trocas iniciais, pois casos de depressão pós-parto passam em branco pela dificuldade dos profissionais de saúde em escutar os sentimentos de ambivalência, dúvida, inadequação, entre tantos outros, na construção da maternidade.

No entanto, como diversas pesquisas sobre interação precoce demonstram, as diferenças individuais observadas nos bebês em sua maneira de interagir com a mãe parecem influenciar o tipo de maternagem que lhes é oferecida, indicando uma reciprocidade nas trocas estabelecidas e não só a ação do desejo parental sobre a criança. Como resultado destas reflexões podemos pensar na clínica das intervenções precoces como uma clínica do acompanhamento simultâneo do psiquismo materno e da interação mãe-bebê, permitindo uma dialética entre a interação fantasmática e a interação real.

Os tempos da prematuridade

A clínica de bebês pré-termo internados pressupõe pensar nas vicissitudes da constituição subjetiva e em como a situação de prematuridade pode ser traumática para os pais e para o bebê pela própria descontinuidade temporal introduzida pelo parto antecipado (prematuro), parto que interrompe o processo de construção do bebê imaginário e confronta os pais com o real orgânico do bebê em uma situação - UTI neonatal - em que a temporalidade é urgente, premente, relacionada à sobrevivência do bebê e não à qualidade de seus cuidados.

Nascer antecipadamente coloca o bebê num mundo diferente e estranho daquele que lhe era conhecido até então. No projeto de pesquisa desenvolvido no Hospital Fernandes Figueira, hospital materno-infantil da Fundação Oswaldo Cruz no Rio de Janeiro, acompanhamos bebês pré-termo e suas famílias durante sua internação em cuidados intensivos neonatais, nascidos entre 28 e 32 semanas gestacionais, até chegarem na idade cronológica de 24 a 36 meses. A primeira parte da pesquisa foi dedicada à intervenção precoce centrada nos bebês internados e em suas famílias e será o objeto do presente trabalho.

Pudemos observar que mesmo o bebê pré-termo em boas condições clínicas ao nascer, e com adequado nível de maturidade, necessita de um certo período para alcançar auto-regulação e equilíbrio em seus diferentes sistemas em função 


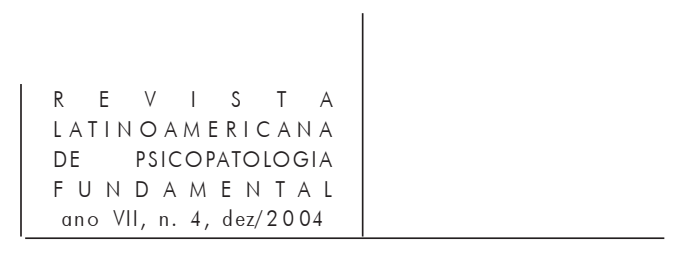

destas novas solicitações. Frente às exigências de processos fisiológicos como respirar, sugar e manter a temperatura, o bebê necessita privilegiar a manutenção e bem-estar biológico, em detrimento de um investimento de respostas a partir das estimulações afetivas e sociais enviadas por seu ambiente de cuidados. Ou seja, o fato de ter nascido antes do tempo previsto exige do pequeno recémnascido respostas especiais ao que lhe é oferecido pelo exterior (mesmo que em alguns momentos suas vivências corporais e sensações táteis sejam causadas pela tecnologia dos aparelhos da UTI neonatal), que permitam sua sobrevivência ou a manutenção de seu estado clínico estável.

Sendo assim, podemos pensar no parto prematuro como uma descontinuidade temporal dupla para o bebê, pois ao mesmo tempo provoca uma descontinuidade temporal que dificulta a instauração de cuidados parentais que facilitem ao bebê a transição e a adaptação à vida extra-uterina, assim como antecipa uma prontidão ao exigir do bebê que ultrapasse sua fragilidade e imaturidade e se adapte às novas condições impostas pelo nascimento antecipado. Podemos exemplificar este paradoxo em termos da idade gestacional que o bebê possui ao nascer. Dependendo do número de semanas gestacionais no nascimento, seus sistemas estarão mais ou menos habilitados ou competentes para trocas interacionais.

Até o presente momento, estudos como os de Romana Negri (1994), FabreGrenet (1997) e Heidelise Als (apud Fabre-Grenet) indicam que apenas a partir da vigésima-oitava semana o bebê está apto a interagir com o meio, desde que esteja em boas condições clínicas. Para interagir com um adulto, o pré-termo deve apresentar uma estabilidade autônoma relativa (respiração, oxigenação) que não lhe faça exigências suplementares.

Segundo Als (ibid.), o bebê possui diferentes sub-sistemas em seu funcionamento, permitindo uma organização gradativa para fazer frente à sua participação no processo vital. Estes diferentes sub-sistemas estão em contato com o meio e entre eles mesmos, possibilitando ao bebê cuidar de suas funções básicas e estar em comunicação com o meio ambiente. O primeiro sub-sistema denominado de autônomo, aparece na sexta semana gestacional e é responsável pelas funções vitais como a respiração, o ritmo cardíaco, a cor e ao aspecto da pele, sinais viscerais. Ele é seguido pelo sub-sistema motor que compreende o tônus muscular, a postura, os movimentos voluntários e involuntários. O subsistema de organização do sono e vigília é o próximo a surgir, sendo responsável pelos estados de consciência e pelos esquemas de transição observados entre estes diferentes estados. A interação social aparece a partir da capacidade do organismo de permanecer em estado de alerta para receber as informações cognitivas, sociais e emocionais e, em contrapartida, provocar e modificar estes contatos do mundo a seu redor. No entanto, a capacidade de comunicação do bebê, que se caracteriza pelo olhar e pelo sorriso, só aparece por volta da 


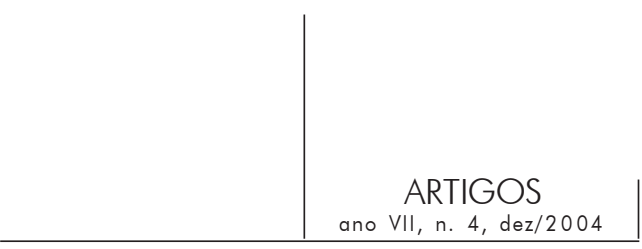

vigésima-quinta/vigésima-oitava semana, estando plenamente eficaz após a trigésima-segunda semana.

Ou seja, como pensar a clínica com bebês pré-termo nascidos com 24/25 semanas de idade gestacional, pouco interativos e responsivos ao meio, provocando preocupação e temor em função de suas necessidades tão especiais, mas impossibilitados de engajar seus cuidadores em um processo de sedução e interação que facilite a instauração de vínculos?

Sem dúvida a aproximação deste bebê real ao bebê imaginário construído durante a gestação demandará um tempo de elaboração dos pais que muitas vezes transcende o tempo da internação. É como se muitos pais esperassem uma garantia ou, pelo menos, sinais consistentes por parte do bebê de que podem investir afetivamente nesta relação, sem ameaças de perda. $\mathrm{O}$ tempo de internação é vivenciado pelos pais como um tempo de exclusão de sua vida familiar e social, pois enquanto seus familiares retomam sua rotina, os pais do bebê prematuro permanecem na UTI neonatal, muitas vezes divididos e ambivalentes em relação aos cuidados dispensados ao bebê internado e aos outros filhos.

A temporalidade frenética de uma UTI neonatal, com barulhos, aparelhos em funcionamento, diversos profissionais em estado de alerta, contribui para o esvanecimento da dimensão subjetiva do bebê, já que sua passividade ao ser colocado como objeto de cuidados da equipe médica e de enfermagem, dificulta a instauração de um circuito pulsional, de uma amarração simbólica que permita à mãe se reconhecer como mãe daquele bebê específico. Em vez do sentimento de triunfo advindo de se pensar o nascimento como o resultado de um processo e da necessidade do bebê sair de um universo limitado (útero), o parto prematuro instaura uma sensação de fracasso na mãe e dificulta um olhar narcísico que veja além do real orgânico do bebê. Neste contexto, pensar no sofrimento dos bebês prematuros significa pensar no risco que correm de não estabelecerem trocas afetivas e não terem a seu dispor uma palavra verdadeira que os situem em relação a seus pais e a eles mesmos.

Poderíamos dizer que a situação de prematuridade dificulta a criação de um espaço de ilusão entre a mãe e o bebê, espaço potencial que permita à mãe se identificar ao bebê e responder às suas necessidades. Intervir precocemente significa então possibilitar que, através de uma intermediação, este espaço possa ser construído, as palavras possam ser veiculadas, permitindo uma amarração simbólica que produza um efeito de alteridade, de subjetividade no bebê. Os diversos tempos que se entrecruzam - a temporalidade retroativa, fantasmática dos pais, a temporalidade de construção e de constituição subjetiva do bebê, a temporalidade urgente que incita à ação da equipe médica e de enfermagem -, podem ser acolhidas e transformadas pelo tempo de elaboração e reflexão presente no trabalho analítico. 


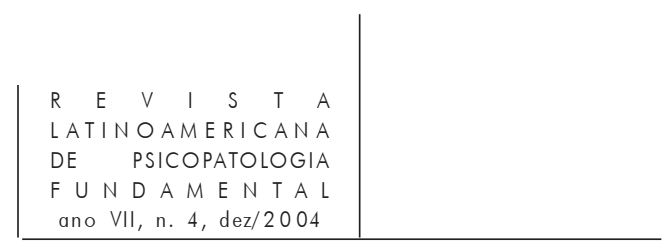

Nesta perspectiva a UTI neonatal não precisa necessariamente ser o palco onde se desenrolam os dramas da prematuridade e onde se produzem as descontinuidades e invasões ambientais, mas pode se transformar em um espaço potencial entre a mãe e o bebê que possibilite que este encontro fundamental se dê, que haja a construção de uma relação silenciosa que permita a continuidade de existência e a elaboração (a posteriori) das marcas destes primeiros tempos.

\section{Referências}

Busnel, M.-C. (org.). A linguagem dos bebês: sabemos escutá-los? São Paulo: Escuta, 1997. Dolto, F. O caso Dominique. Rio de Janeiro: Zahar, 1981.

Druon, C. Ajuda ao bebê e aos seus pais em terapia intensiva neonatal. In: WANDERLEY, D. (org.). Agora eu era o rei: os entraves da prematuridade. Salvador: Ágalma, 1999.

FABre-Grenet, M. As formas de comunicação do recém-nascido prematuro. In: BuSNeL, M.C. (org.). A linguagem dos bebês: sabemos escutá-los? São Paulo: Escuta, 1997.

FERENCZI, S. (1927). Final contributions to the problems and methods of psychoanalysis. New York: Brunner/Mazel, 1955.

Fraiberg, S.; Adelson, E. \& Shapiro, V. Ghosts in the nursery: a psychoanalytic approach to the problems of impaired infant-mother relationships. Journal of the American Academy of Child Psychiatry, v. 14, p. 387-421, 1975.

FREUd, S. (1926[1925]). Inibições, sintoma e ansiedade. In: Edição Standard Brasileira das Obras Psicológicas Completas. Rio de Janeiro: Imago, 1976.

Golse, B. Comunicação oral na Sociedade Brasileira de Psicanálise. Rio de Janeiro, 2000.

O que temos aprendido com os bebês. In: Correa Filho (org.). Novos olhares sobre a gestação e a criança até os três anos. Brasília: L.G.E. Editora, 2002.

Negri, R. The Newborn in the Neonatal Intensive Care Unit. London: The Clunie Press, 1994.

Ogden, T. Os sujeitos da psicanálise. São Paulo: Casa do Psicólogo, 1996.

Piontelli, A. De feto a criança. Rio de Janeiro: Imago, 1995.

Soulé, M. e Cyrulnik, B. A inteligência anterior à palavra. Porto Alegre: Artes Médicas, 1999.

Stern, D. A constelação da maternidade. Porto Alegre: Artes Médicas, 1997. O mundo interpessoal do bebê. Porto Alegre: Artes Médicas, 1992.

WinNicotr, D. (1960). Da pediatria à psicanálise. Rio de Janeiro: Francisco Alves, 1975. O ambiente e os processos de maturação. Porto Alegre: Artes Médicas, 1990.

Zornig, S. Prematuridade e trauma: questões sobre a constituição do sujeito. Tempo Psicanalítico, SPID, Rio de Janeiro, n. 33, 2001. 


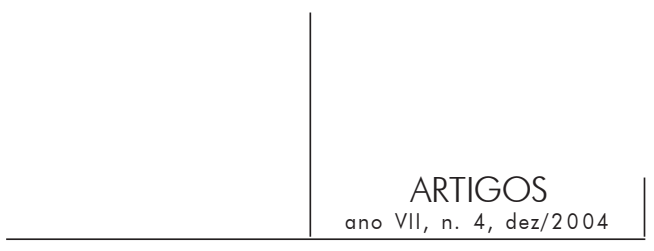

Resumos

Este trabajo tiene por objetivo discutir la clínica psicoanalítica con bebés, y tiene como referencia un proyecto de investigación desarrollado con bebés prematuros internados y sus familias (Hospital Fernandes Figueira/Fiocruz). Parte de la concepción freudiana sobre el desamparo estructural del ser humano para analizar las vicisitudes de la constitución del sujeto a partir de los diferentes tiempos que se instalan en los primordios de la subjetividad: un tiempo de retroacción relacionado a los fantasmas y deseos de los padres; un tiempo de construcción (Winnicott) y de continuidad, relacionado a los cuidados maternos; y un tiempo discontinuo traumático que se refiere a los bebés nacidos prematuramente.

Palabras claves: Clínica psicoanalítica, bebés prematuros, constitución del sujeto, intervención precoz

Le présent travail a pour objectif de discuter la clinique psychanalytique avec des bébés, avec pour référence un projet de recherche mené avec des bébés prématurés hospitalisés et leurs familles (Hôpital Fernandes Figueira/Fiocruz). Il s'appuie sur la conception freudienne de la détresse structurelle de l'être humain pour analyser les vicissitudes de la constitution du sujet à partir des différents temps s'installant dans les origines de la subjectivité : un temps de rétroaction lié aux fantasmes et aux désirs parentaux, un temps de construction (Winnicott) et de continuité lié aux soins maternels et enfin un temps discontinu, traumatique, qui se réfère aux bébés nés prématurément.

Mots clés: Clinique psychanalytique, bébés prématurés, constitution du sujet, intervention précoce

This paper discusses psychoanalytic practice with babies based on treatment carried out with pre-term babies and their families during their stay in the intensive care unit at a public hospital in Rio de Janeiro. Taking Freud's concept of the infant's structural dependence on others as a point of reference, it discusses the different concepts of time in the construction of the baby's subjectivity, including the parents' unconscious fantasies and narcissistic investment in the yet unborn baby, the relationship between the baby and maternal holding (Winnicott), and traumatic, abrupt timing related to prematurity.

Key words: Psychoanalytic practice, pre-term babies, subject's constitution, early intervention

Versão inicial recebida em abril de 2003

Versão revisada recebida em março de 2004 